\title{
There's Plenty of Room at Bottom of Biostatistics and Biometrics
}

\author{
Acharjee $S^{*}$ \\ Department of Mathematics, Debraj Roy College, India
}

Submission: December 16, 2017; Published: April 26, 2018

*Corresponding author: Santanu Acharjee, Economics and Computational Rationality Group, Debraj Roy College, Golaghat-785621, Assam, India, Email: sacharjee326@gmail.com/santanuacharjee@rediffmail.com

\section{Opinion}

Renowned physicist Richard Feynman delivered a talk in 1959 at Caltech with title "There's plenty of room at bottom". This talk was criticized for almost thirty years and it was hard to believe until early 1990. At present, this unusual talk of Feynman is considered as the foundational talk on "nanotechonology" [1]. Being unfamiliar of biological terminologies, it is customary for me to use mathematical terminologies. Readers of this article may find opinions of this article absurd for the time being, but we shall try to develop some sketches of ideas for future in these directions.

Most of statistical ideas deal with quantitative analyses. Qualitative analyses are often difficult for existing statistical methodologies to deal with. For example; if we compare quantities relative to attributes, then it is difficult to do statistical analyses. Thus, it must be assumed that presence of uncertainties in data with respect to attributes make tasks of statistical analyses most difficult. Biological data are related to attributes, which are present in terms of hormones, symptoms, molecules etc. So, there are scopes of development of statistical ideas and their applications in biology and associated areas.

Prior to 1999, there were four mathematical tools to deal with uncertainties viz. probability theory, fuzzy set theory, rough set theory and the theory of interval mathematics [2]. Fuzzy set deals with membership values. Membership values are often difficult to consider and varies from person to person, which yields problems in decision making, data analyses etc. Thus, the faults which are present in Fuzzy set, led Molodtsov [3] to introduce soft set theory in 1999.

\section{Definition 1}

[3] A soft set $\mathrm{F}_{\mathrm{A}}$ on the universe $\mathrm{U}$ is defined by the set of ordered pair $F_{A}=\left\{\left(x, f_{a}(x)\right): x \in E, f_{A}(x) \in P(U)\right\}$, where $f_{A}=E \rightarrow P(U)$ such that $f_{A}(x)=\phi$ if $x \notin \boldsymbol{A}$.

Here, $f_{A}$ is called an approximate function of the soft set $F_{A}$. The value of $f_{A}(x)$ may be arbitrary. Some of them may be empty, some may have non-empty intersection. We will denote the set of all soft sets over $U$ as $S(U)$. Above definition clearly shows presence of attributes, words, adjectives, [0,1] etc. One may refer to Acharjee [4] for extensive review on soft set theory and its hybrid structures for researchers other than mathematicians.

If we consider Pearson's correlation coefficient, then difficulties arise related to data in terms of attributes. Either two attributes may be similar, "semantically" similar, or dissimilar. Statistical methodologies fail to distinguish between these three characteristics of attributes. Hence, can we say that biostatistics has scopes to adopt new statistical methodologies? Of course "yes". Prior to Acharjee and Mordeson [5], many statistical methodologies were developed in terms of uncertainties of mathematics viz. fuzzy set, intuitionistic fuzzy sets etc. These methodologies have focused mostly on degrees of membership, degree of non-memberships etc. with modified statistical formulations. Every soft set can be represented in tabular form in terms of 0 and 1. In [5], Acharjee and Mordeson connected attributes with statistical methodologies in the presence of binary digits 0 and 1 . Though, significance of these methodologies has been shown in human trafficking, yet the application part shows that data were divided by attributes related to vulnerability and government responses in "The Global Slavery Index, 2016". In a similar manner, biological data are often related with symptoms, drugs, hormonal activities, molecules etc. So, extensive analysis for the development of soft statistics is seemed necessary for biostatisticians. In the meanwhile, Acharjee and Mordeson [5] have included of mathematical ideas from economics viz. utility theory, to connect human choice behaviour and its significance in statistical analyses are shown. Let us think about occurrence of a biological activity, and a researcher has preference among the attributes, which are responsible for the activity. Acharjee and Mordeson [5] developed methodologies by using preference, which reduce entire data to the specific data which signify preference and attributes simultaneously.

Let us consider a case of biological activity, where some causes of this activity are unknown and a researcher will have to guess about the activity in terms of attributes and degree of membership. Thus, fuzzy soft set is the suitable tool to deal with 
this biological activity. But, fuzzy statistical methodologies are not suitable tool to deal with this case. Moreover, there is a lack of methodology to analyze this case. So, Acharjee et al. [6] have used fuzzy -cut to develop fuzzy soft statistical ideas with utility. For the biologists, let us assume that $\alpha$-cut is the restriction in the data in the sense of a layman, which they will have to reduce for their analyses or they will have to overcome in the course of time to have the necessary data from a huge data. Similarly, presence of degree of non-membership as well as degree of membership related to attributes together yields intuitionistic fuzzy soft statistics [7].

Thus, we can see that classical statistical methodologies may fail in many cases, where qualities are present. Biostatisticians should focus on these tools and think to develop these areas for the betterment of human race. In biometrics, ideas of similarity play crucial roles. During measures of similarities between two objects, various existing definitions focus on common domain of two objects relative to each of them independently. The value of similarity measure lies between 0 and 1 . It is often observed that certain negligible changes in the objects yield difficulties during recognition of biometrics. These types of difficulties can be dealt with similarities of soft sets. In [8], Acharjee encountered some errors and redefined similarity measures of soft set based on Kharal's definitions [9]. Soft similarity and associated structures have scopes to find similarities between the face of a person after burn and his original face before the burn.

There are many cases similar to this, where biometric processes fail to provide suitable methods of recognitions. These problems are to overcome for the purposes of defence security system of a country. Thus, if one develops biometric tools and methodologies based on attributes, then soft similarities and associated structures will be helpful to indentify even after some deformations of one face or thumb etc. Significance of our justifications can be understood from the prospective of wounded face of a defence officer and security password related to confidential top secret's defence account, which is nothing but his original face before the wound. Hence, improvisations of security systems are mandatory.
At the end of this article, we want to focus on aspects of nanotechnology for biometrics. Uses of nanotechnology in biometrics can be found in [10]. Multisets deal with multiplicity of elements, thus theoretical studies on nanotechnology have scopes to use soft multiset topology. Without going for mathematical details, intuitively we can say that, if number of atoms matter in nanotechnology, then multiset theoretic topological study will gave the theoretical knowledge about behaviour of atoms in nano level of nanotechnology. In similar manner, we can say same for soft multiset topology. Thus, we want to conclude with above sketches of ideas which may be beneficial for biostatisticians and we hope that this short paper may have some though provoking impacts in future.

\section{References}

1. https://en.m.wikipedia.org/wiki/History_of_nanotechnology

2. Molodtsov D (1999) Soft set theory- first results. Comput Math Appl 37: 19-31.

3. Cagman N, Karatas S, Enginoglu S (2011) Soft topology. Comput Math Appl 62: 351-358.

4. Acharjee S (2018) On connections of soft set theory with existing mathematics of uncertainties: a short discussion for nonmathematicians with respect to soft set theory, New Mathematics and Natural Computation 14: 1.

5. Acharjee S, Mordeson JN (2017) Soft statistics with respect to utility and application to human trafficking, New Mathematics and Natural Computation (World Scientific) 13(3): 289-310.

6. Acharjee S, Sarma DJ, Hanneman RA, Mordeson JN, Malik DS (2017) Fuzzy soft statistics via fuzzy -cut, utility and application to human trafficking.

7. Acharjee $S$ (2017) Intuitionistic fuzzy soft statistics via utility.

8. Acharjee S (2017) New results for Kharal's similarity measures of soft sets, New Mathematics and Natural Computation 13(01): 55-60.

9. Kharal A (2010) Distance and smilarity measures for soft sets, New Mathematics and Natural Computing 6(3): 321-334.

10. Raiesdana S, Gholpayeghani MH, Nasrabadi AM (2007) Biometric nanotechnology and nonlinear dynamics, First International Conference on Quantum, Nano, and Micro Techonologies DOI: 10.1109/ICQNM.2007.4

\section{Your next submission with Juniper Publishers will reach you the below assets}

- Quality Editorial service

- Swift Peer Review

- Reprints availability

- E-prints Service

- Manuscript Podcast for convenient understanding

- Global attainment for your research

- Manuscript accessibility in different formats

( Pdf, E-pub, Full Text, Audio)

- Unceasing customer service

Track the below URL for one-step submission

https://juniperpublishers.com/online-submission.php 